Сегментированный анализ динамических рядов официальных статистических показателей остеоартрита в 1994-2018 гг. в России, Северо-3ападном федеральном округе и Архангельской области

\author{
М.В. Макарова, М.Ю. Вальков
}

ФГБОУ ВО «Северный государственный медицинский университет» Минздрава России 163069, Российская Федерация, Архангельск, Троицкий просп., 51

Northern State Medical University 163069, Russian Federation, Arkhangelsk, Troitsky avenue, 51

Контакты: Макарова Мария Васильевна, mtim10@gmail.com

Contacts: Maria Makarova, mtim10@gmail.com

Поступила 22.03.2020 Принята 31.08.2021
Для совершенствования ревматологической службы в Российской Федерации (РФ) необходимо определить истинные масштабы первичной и общей заболеваемости остеоартритом (ОА).

Цель исследования - детализированная оценка трендов динамики заболеваемости остеоартритом в Российской Федерации, Северо-Западном федеральном округе (СЗФО) и Архангельской области (АО). Материалы и методы. Оценивали тренды динамики первичной и общей заболеваемости ОА в РФ, СЗФО и АО в период 1994-2018 гг. на основании данных ежегодных статистических отчетов Министерства здравоохранения РФ (форма № 12). Данные о численности населения АО получены в региональном бюро статистики - Архангельскстат, по СЗФО и РФ - из свободно доступных статистических сборников Росстата. Анализировали показатели взрослого населения (старше 18 лет). Для оценки временных трендов применяли сегментированный анализ с помощью программы Joinpoint Regression Program (National Cancer Institute, США) для анализа линейных трендов, оценки их статистической значимости и выявления временных точек их смены (joinpoints).

Результаты. В период с 2004 по 2012 г. в РФ наблюдалось снижение числа ежегодно выявленных случаев ОА, при этом общая заболеваемость ОА стабильно росла; в 2016 г. зафиксировано снижение количества случаев ОА по СЗФО и АО. Анализ показал несовпадение трендов первичной заболеваемости ОА в РФ, СЗФО и АО, которая носила нелинейный хаотичный характер. Во всех территориях общая заболеваемость росла. В РФ период с 2004 по 2008 г., когда первичная заболеваемость ОА резко падала, отмечен стабильным ростом общей заболеваемости с 2041,6 до 3383,3 случая на 100 тыс. населения.

Заключение. Анализ официальной статистической информации о первичной и общей заболеваемости ОА показывает существенную вариацию показателей, их колебания никак не связаны с изменениями в практике диагностики и лечения этого заболевания и могут быть обусловлены пробелами в его регистрации. Улучшение эпидемиологической оценки ОА возможно при внедрении системы персонифицированного учета пациентов - регистра ОА.

Ключевые слова: остеоартрит, Архангельская область, первичная заболеваемость, общая заболеваемость Для цитирования: Макарова МВ, Вальков МЮ. Сегментированный анализ динамических рядов официальных статистических показателей остеоартрита в 1994-2018 гг. в России, Северо-Западном федеральном округе и Архангельской области. Научно-практическая ревматология. 2021;59(5):584-591.

\section{SEGMENTED ANALYSIS OF OFFICIAL STATISTICAL INDICATORS DYNAMIC SERIES FOR OSTEOARTHRITIS IN 1994-2018 IN RUSSIA, THE NORTH-WESTERN FEDERAL DISTRICT AND THE ARKHANGELSK REGION}

Maria V. Makarova, Mikhail Yu. Valkov

To improve the rheumatology service in the Russian Federation, it is necessary to determine the true extent of primary and general incidence of osteoarthritis (OA).

The aim of the study is a detailed assessment of trends in the dynamics of OA incidence in the Russian Federation, the North-Western Federal district (NWFD) and the Arkhangelsk region (AR).

Materials and methods. We evaluated trends in the dynamics of both incidence and prevalence of OA in the Russian Federation (RF), NWFD and AR in the period 1994-2018 based on data from the annual statistical reports of the Ministry of health of the Russian Federation (form 12). Data on the population of AR were obtained in the regional Bureau of statistics - Archangelskstat, for the northwestern Federal district and the Russian Federation from freely available statistical collections of Rosstat. We analyzed the indicators of the adult population (over 18 years old). To evaluate time trends, we used segmented analysis using the Joinpoint Regression Program (National Cancer Institute, USA) to analyze linear trends, evaluate their statistical significance, and identify time points of their change (joinpoints).

Results. In the period from 2004 to 2012 in Russia was a decline in the number of annually detected cases of OA, the prevalence of OA increased steadily in the 2016 year recorded a decline in the number of cases of OA in NWFD and AR. The analysis showed a discrepancy in the trends of incidence of OA in the Russian Federation, the northwestern Federal district and AR, which was nonlinear and chaotic. In all territories, the prevalence was increasing. In the Russian Federation, the period from 2004 to 2008, when the primary incidence of OA fell sharply, was marked by a stable increase in the prevalence from 2041.6 to 3383.3 per 100 thousand population.

Conclusion. Analysis of official statistical information on the both incidence and prevalence of OA shows a significant variation in indicators, their fluctuations are not related to changes in the practice of diagnosis and treatment of this disease and, most likely, are associated with gaps in its accounting. Improving the epidemiological assessment of OA is possible with the introduction of a system of personalized patient registration-the osteoarthritis registry. Key words: osteoarthritis, Arkhangelsk region, incidence, prevalence 
For citation: Makarova MV, Valkov MYu. Segmented analysis of official statistical indicators dynamic series for osteoarthritis in 1994-2018 in Russia, the North-Western Federal district and the Arkhangelsk region. Nauchcno-Prakticheskaya Revmatologia = Rheumatology Science and Practice .

\section{Введение}

Остеоартрит (ОА) является наиболее часто встречающимся ревматическим заболеванием. ОА включен в ХІІІ класс Международной классификации болезней 10го пересмотра (МКБ-10). По оценкам Всемирной организации здравоохранения, $10 \%$ населения мира страдают этим заболеванием [1]. У 21 млн американцев (7\% всего населения США) установлен диагноз ОА [1]. В 1994 г. число официально зарегистрированных больных ОА составляло 951257 человек (0,9\% населения), к 2009 г. их количество превысило 3,8 млн (1,8\% населения), а в 2016 г. - достигло 4,6 млн (3\% населения) [2-5]. Ежегодно в России выявляют более 600 тыс. новых случаев ОА [3]. Согласно прогнозам, в следующие два десятилетия число больных ОА в мире увеличится в 4 раза [4]. Социальная значимость заболевания определяется его необратимым прогрессированием и высокой частотой инвалидизации: в 2012 г. инвалидность впервые установлена у 12,3\% больных ОА [4]. Удельный вес инвалидов вследствие болезней опорно-двигательной системы в РФ составил в среднем 7,3\%. У $38 \%$ из этих больных инвалидность установлена по поводу ОА 3-4-й стадии [5]. Поскольку первичная и общая заболеваемость ОА прямо связаны с возрастом и увеличением продолжительности жизни, в перспективе ожидается дальнейший прирост числа больных ОА.

Наиболее достоверная информация о заболеваемости ОА может быть получена только в результате специально организованных эпидемиологических исследований. По данным проведенного в конце 1970-х гг. многоцентрового советского исследования, в котором анализировались результаты анкетирования работников заводов разных регионов страны и данные официальной статистики, общая заболеваемость болезнями костно-мышечной системы (БКМС) среди взрослых составила 70,0 на 1000 населения [6]. С учетом того, что в последние четыре десятилетия крупных исследований по мониторингу эпидемиологической ситуации в Российской Федерации (РФ) не проводилось, основным источником информации о заболеваемости служит официальная статистика государственной системы здравоохранения. По официальным данным 2016 г., общая заболеваемость БКМС составляет 21,3 на 1000 населения, что значительно ниже данных 40-летней давности [5].

До настоящего времени не существует единого регистра пациентов с установленным диагнозом ОА; учет данных пациентов ведется по форме № 12 «Сведения о числе заболеваний, зарегистрированных у пациентов, проживающих в районе обслуживания медицинской организации», утвержденной Приказом Росстата от 24.12.2018 № 773. Такие статистические данные, сформированные на основании формы № 12 ежегодного отчета учреждений здравоохранения, отражают лишь общие тенденции первичной и общей заболеваемости, не учитывая при этом особенности распределения нозологии по полу и возрастным периодам [7].

Для совершенствования ревматологической службы в РФ необходимо определить истинные масштабы первичной и общей заболеваемости для определенных нозо- логий. Наметившиеся в последние годы демографические сдвиги, обусловленные трудовой миграцией, ростом числа лиц пенсионного возраста, нестабильные экономические условия являются поводом для анализа заболеваемости ОА в свете изменяющихся социально-экономических факторов.

Цель настоящей работы - детализированная оценка трендов динамики заболеваемости остеоартритом в Российской Федерации, Северо-Западном федеральном округе (СЗФО) и Архангельской области (АО).

\section{Материалы и методы}

На проведение исследования было получено разрешение комитета по этике ФГБОУ ВО «Северный государственный медицинский университет» Минздрава России (г.Архангельск) № 10 от 21.12.2011. Оценивалитрендыдинамики первичной и общей заболеваемости (распространенности) ОА в РФ, СЗФО и АО в период 1994-2018 гг. по данным ежегодных статистических отчетов Министерства здравоохранения (МЗ) РФ (форма № 12) [7].

Процедура регистрации первичного ОА регламентируется приказом МЗ РФ от 15.12.2014 № 834н «Об утверждении унифицированных форм медицинской документации, используемых в медицинских организациях, оказывающих медицинскую помощь в амбулаторных условиях, и порядков по их заполнению» (Приложение № 4, форма 025-1/y). До 2004 г. учет заболеваний проводили на основании «Статистического талона для регистрации заключительных (уточненных) диагнозов» по форме 025-2/у (Приказ М3 СССР от 04.10.1980 № 1030 «Об утверждении форм первичной медицинской документации учреждений здравоохранения»). В период с 2004 по 2014 г. действовал приказ Министерства здравоохранения и социального развития РФ от 22.11.2004 № 255 «О Порядке оказания первичной медико-санитарной помощи гражданам, имеющим право на получение набора социальных услуг» (учетная форма 025-12/y «Талон амбулаторного пациента»).

В соответствии с действующим приказом информацию по всем впервые выявленным случаям ОА заносит в учетную форму 025-1/y «Талон пациента, получающего медицинскую помощь в амбулаторных условиях» врачспециалист и (или) медицинский работник со средним профессиональным образованием, работающий на приеме с соответствующим специалистом. Талон, согласно п. 1.1 Приложения № 4 к приказу, формируется в форме электронного документа, подписанного с использованием усиленной квалифицированной электронной подписи врача. Данные талонов сводят в конце отчетного года в единую форму № 12 в каждом лечебном учреждении для прикрепленного населения на конец отчетного года. На основании этих данных каждый регион формирует единый отчет для вышестоящего подразделения Федеральной службы государственной статистики.

Врач-специалист устанавливает диагноз ОА при рентгенологической верификации на основании критериев Altman при исключении системных ревматических заболеваний [8]. 
Показатели и методы оценки. Рассчитывали показатели, доступные в рамках эпидемиологического исследования: 1) первичная заболеваемость - отношение ежегодного числа вновь выявленных случаев ОА к среднегодовой численности населения (СГЧН, среднее между данными на 1 января текущего и следующего годов) на 100000 человек населения АО; 2) общая заболеваемость (распространенность) - отношение общего количества пациентов с установленным диагнозом ОА, состоящих на учете, к СГЧН. Для вычисления первичной и общей заболеваемости данные о численности населения АО и его составе по полу и возрасту были получены в региональном бюро статистики - Архангельскстат [9-17]. Полученные данные сравнивали с соответствующими показателями в РФ и СЗФО, которые брали из свободно доступных статистических сборников Росстата [18-21]. Анализу подвергались данные в когорте взрослого населения (18 лет и старше).

Для оценки временных трендов применяли сегментированный анализ с помощью программы Joinpoint Regression Program, v. 4.7.0.0 (National Cancer Institute, США). Этот математический инструмент позволяет выявить линейные тренды, оценить их статистическую значимость и обнаружить временные точки их смены (joinpoints), что дает возможность связать последние с изменениями в практике регистрации и диагностики заболевания на популяционном уровне.

Методом пермутации программа выбирает наименьшее количество точек соединения трендов, пока при добавлении еще одной точки улучшение не становится статистически значимым. Таким образом, в окончательной модели каждую из joinpoints и соответствующие изменения в трендах можно интерпретировать как значимые. Предельным количеством точек смены трендов для сегментированного анализа было установлено четыре. Различия между временными периодами с различными линейными трендами считали статистически значимыми при $p<0,05$.

\section{Результаты}

В течение трех последних десятилетий в РФ и отдельных ее регионах наблюдается неуклонное повышение первичной заболеваемости ОА (рис. 1). Однако этот показатель широко варьирует даже в больших популяциях. Так, в период с 2004 по 2012 г. в РФ наблюдалось логически трудно объяснимое снижение числа ежегодно выявленных случаев ОА.

При этом в тот же период во всех определенных для анализа территориях наблюдался довольно стабильный рост общей заболеваемости ОА (рис. 2). Только в 2016 г. было зафиксировано труднообъяснимое снижение количества случаев ОА как по СЗФО, так и в АО при стабильных показателях в целом по России.

Результаты анализа трендов показателей первичной заболеваемости ОА в РФ, СЗФО и АО с помощью сегментированной регрессии приведены на рисунке 3 .

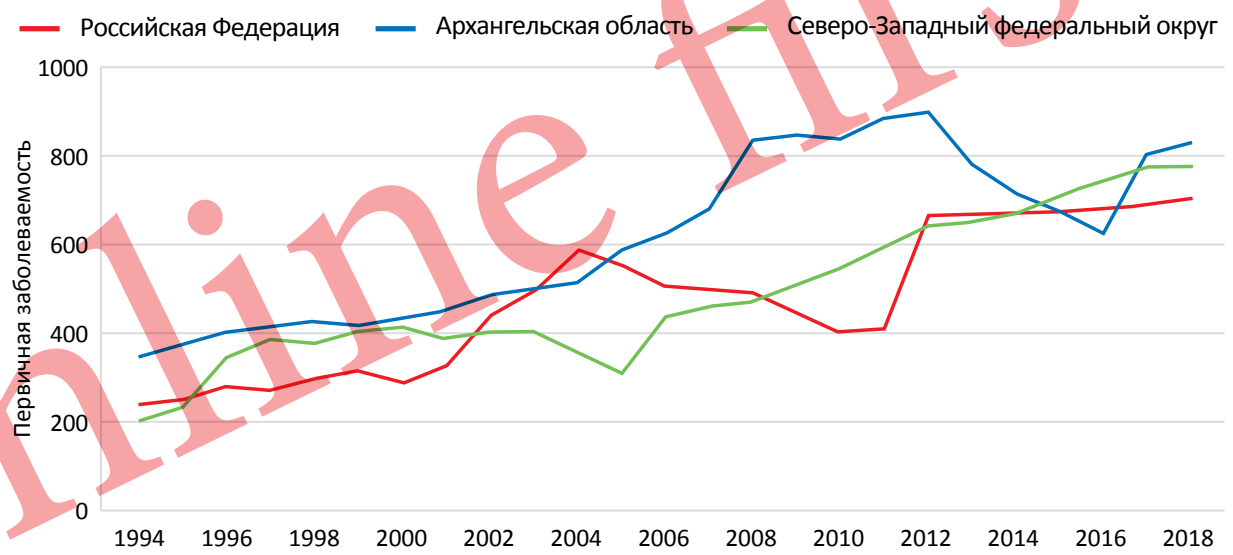

Pис. 1. Динамика первичной заболеваемости остеоартритом в Российской Федерации, Северо-Западном федеральном округе и Архангельской области в 1994-2018 гг., грубые показатели по данным Госкомстата [19-21]

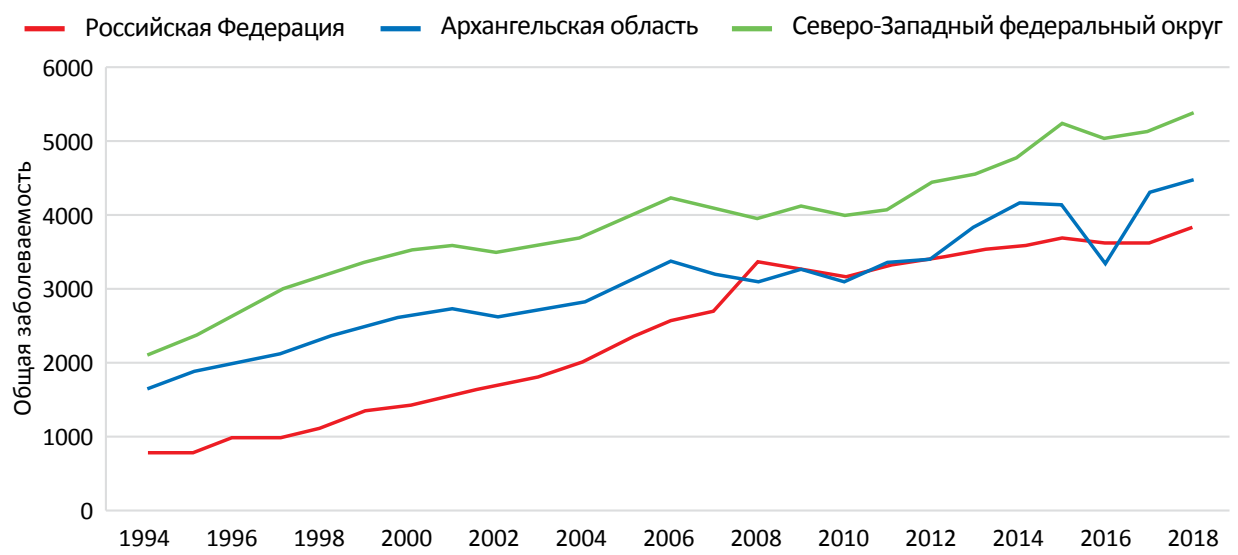

Pис. 2. Динамика общей заболеваемости (распространенности) остеоартритом в Российской Федерации, Северо-Западном федеральном округе и Архангельской области в 1994-2018 гг., грубые показатели по данным Госкомстата [19-21] 

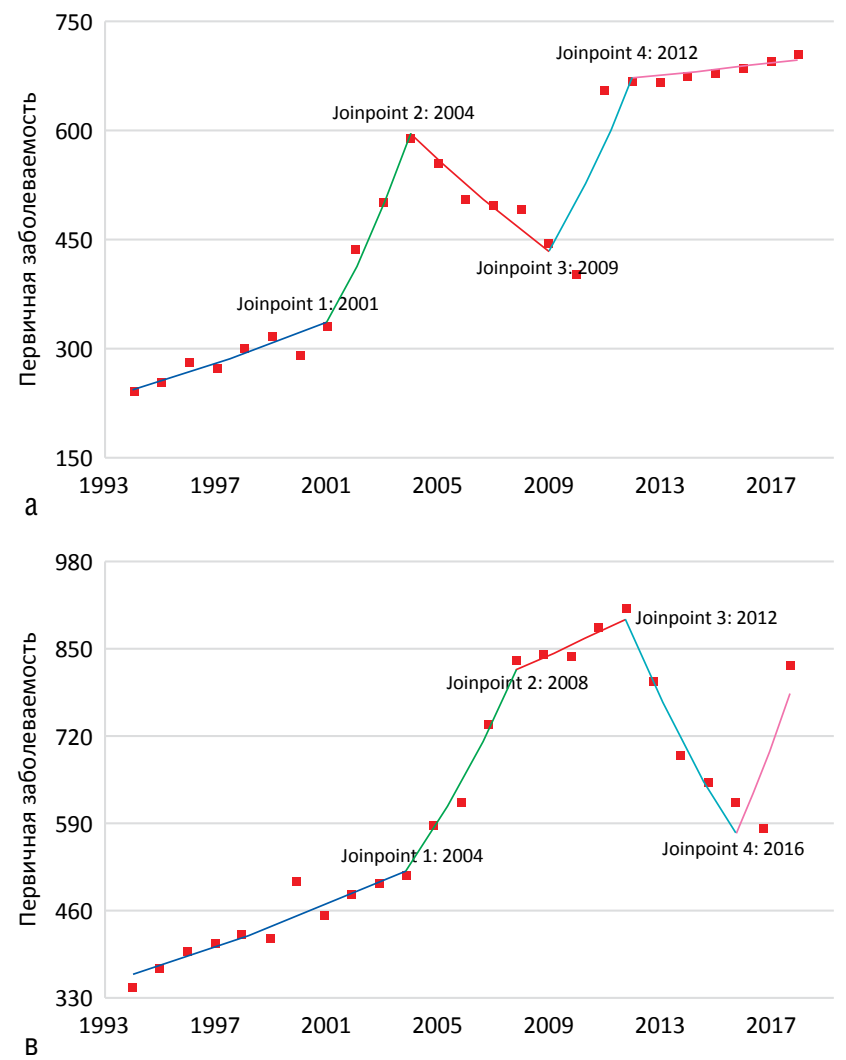

Анализ показал сушественное несовпадение трендов первичной заболеваемости ОА в РФ, СЗФО и АО. Так, с 2004 по 2008 г. в РФ после периода повышения первичной заболеваемости регистрировался ее статистически значимый спад на $6,2 \%$ в год, сменившийся резким подъемом с 486,9 до 669,3 на 100 тыс. населения в 2012 г. С этого перелома тренда показатели первичной заболеваемости ОА в РФ растут стабильно на $0,6 \%$ в год. Такие существенные изменения трендов первичной заболеваемости ОА были совсем не характерны для СЗФО, где после некоторых вариаций трендов первичная заболеваемость ОА после того же 2004 г. стабильно росла - с 310,5 до 772,9 на 100 тыс. населения в 2018 г. - на 5,6\% ежегодно. В период после 2004 г. в АО регистрировался рост первичной заболеваемости на 3,5-12,0\% в год до 2012 г., затем показатель резко снизился - с 834,2 до 623,5 на 100 тыс. населения в 2016 г., после чего последовал настолько же резкий его рост до 827,2 на 100 тыс. населения в 2018 г.

На рисунке 4 представлены результаты сегментированного анализа динамики общей заболеваемости ОА в РФ, СЗФО и АО. Во всех территориях общая заболеваемость росла. Значения этого показателя в 2000 и 2018 гг. составляли 1427,6 и 3852,$5 ; 3546,0$ и 5398,6; 2679,0 и 4490,1 на 100 тыс. населения для РФ, СЗФО и АО соответственно. При этом, в отличие от первичной заболеваемости, показатель общей заболеваемости ОА варьировал в исследуемый период не столь сушественно: ежегодный прирост составляет 3,4-10,5\% для всех территорий.

В целом наблюдается отсутствие взаимосвязи между трендами первичной и общей заболеваемости внутри территорий. Так, в РФ в период с 2004 по 2008 г., когда первичная заболеваемость ОА резко падала, отмечен стабильным ростом общей заболеваемости с 2041,6 до 3383,3 на 100 тыс. населения, несмотря на то, что доля

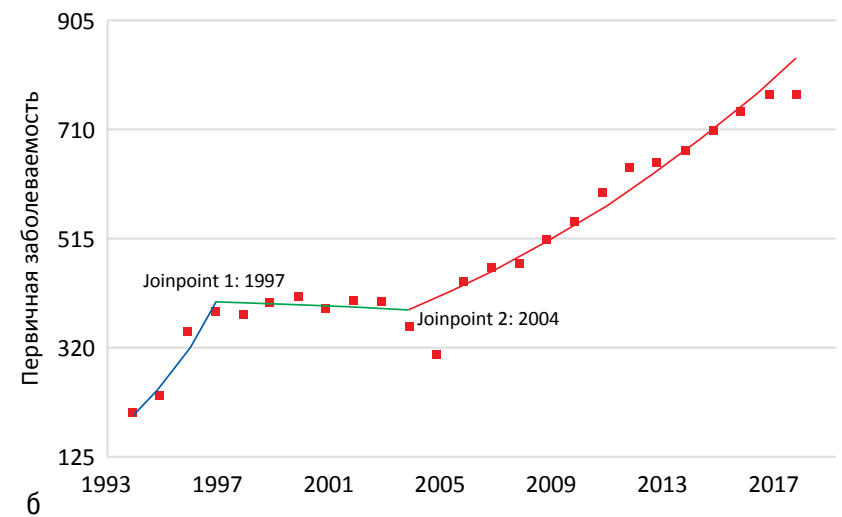

Рис. 3. Динамика первичной заболеваемости остеоартритом за период 1994-2018 гг., сегментированная регрессия, стабильные регрессионные модели (Joinpoint v. 4.7.0.0): a - Российская Федерация, четыре точки сопряжения; б - Северо-Западный федеральный округ, две точки сопряжения; в - Архангельская область, четыре точки сопряжения

первичной заболеваемости в общей составляет 20-25\%. Подобное несоответствие можно отметить и на других анализируемых территориях.

\section{Обсуждение}

В настоящей статье представлен анализ трендов первичной и общей заболеваемости остеоартритом в РФ, СЗФО и АО в период 1994-2018 гг. на основе данных официальной формы государственной отчетности № 12. Тренды общей заболеваемости, как следует из их сегментированного анализа, в целом совпадали в трех анализируемых популяциях. Однако установлены статистически значимые вариации трендов первичной заболеваемости, существенно отличающиеся друг от друга по направленности и временным точкам их излома в РФ, СЗФО и АО. При общей тенденции старения населения РФ и повышения риска ОА только вследствие этого [22] отмечались периоды статистически значимого снижения уровней первичной заболеваемости.

Можно полагать, что диагностика первичного ОА могла улучшиться после введения в 2013 г. единых клинических рекомендаций Ассоциации ревматологов России по диагностике и лечению ОА [23]. Однако тренды первичной заболеваемости в РФ и СЗФО после этого не менялись, а в АО показатель снизился. Возможно, это связано с неточностями в ранее проводимой диагностике заболеваний.

Колебания заболеваемости ОА на уровне РФ и АО также могут быть связаны с низкой обеспеченностью врачамиревматологами и терапевтами, которая не адаптирована к низкой плотности населения в большинстве регионов РФ, а особенно в СЗФО [24], ростом доходов населения и более частым обращением за помощью в негосударственные 

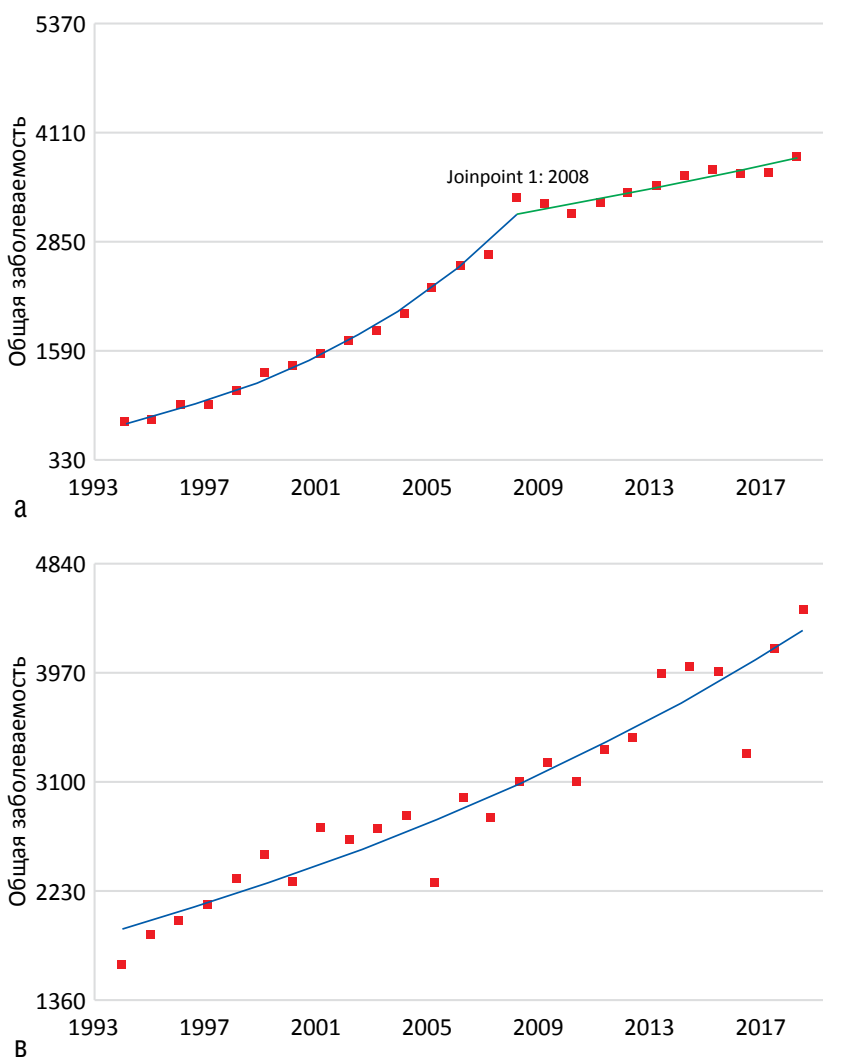

лечебные учреждения, не отчитывающиеся по форме № 12. Наконец, в 2011-2016 гг. в 30 регионах РФ произошло снижение бюджетного финансирования здравоохранения, а наиболее низкие ассигнования на здравоохранение наблюдались в СЗФО, в частности в АО. Вероятно, этим фактом можно объяснить существенное снижение уровня первичной заболеваемости остеоартритом в АО именно в этот период. Позднее перераспределение потоков финансирования привело к росту расходов территориальных фондов обязательного медицинского страхования субъектов РФ в среднем на $183 \%$ за 6 лет [25]. Это способствовало увеличению доступности высокотехнологичной медицинской помощи, включая эндопротезирование суставов у больных ОА, что косвенно могло повлиять на улучшение его диагностики [26].

Таким образом, описанные выше изменения трудно объяснить конкретными событиями федерального или регионального уровней, влияющими на количество больных и частоту регистрации ОА, - по-видимому, они носят случайный характер. Тогда на первый план выходит вопрос о качестве первичной диагностики (регистрации) ОА. Мы полагаем, что сбой регистрации случаев ОА происходит на уровне первичного звена.

Согласно действующим приказам МЗ РФ и профстандартам по отдельным врачебным специальностям, диагноз OА имеют право устанавливать все врачи-специалисты. Исключение составляют врачи общей практики (семейные врачи): согласно приказу Министерства здравоохранения и социального развития РФ от 17.01.2005 № $84 \ll \mathrm{O}$ порядке осуществления деятельности врача общей практики (семейного врача)» [27], такой специалист может только направлять пациентов на консультации к другим врачамспециалистам для стационарного и восстановительного лечения по медицинским показаниям (п. 9).

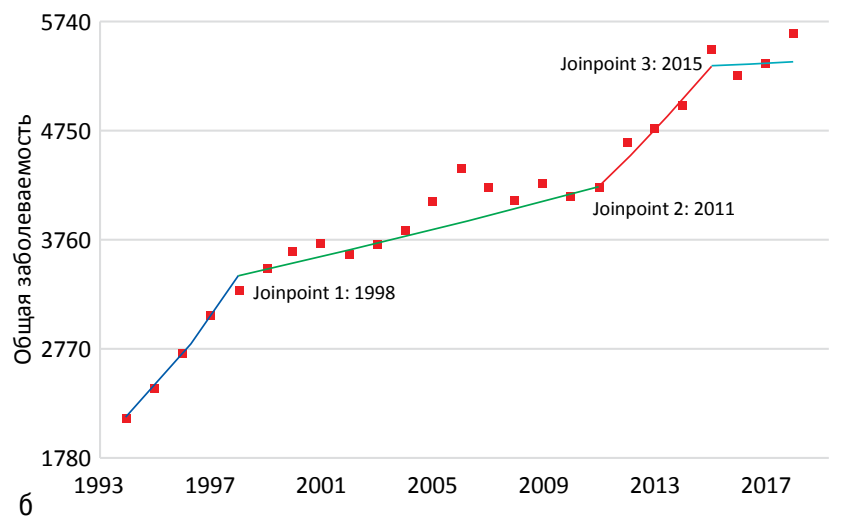

Pис. 4. Динамика общей заболеваемости остеоартритом за период 1994-2018 гг., сегментированная регрессия, стабильные регрессионные модели (Joinpoint v. 4.7.0.0): a - Российская Федерация, одна точка сопряжения; б - Северо-Западный федеральный округ, три точки сопряжения; в - Архангельская область, нет точек сопряжения

Профессиональные стандарты для врачей-специалистов утверждены приказом Министерства труда и социальной защиты РФ от 12.11.2018 № 698н [28]. Именно в этом документе определена основная цель вида профессиональной деятельности врача - «..профилактика, диагностика, лечение травм, заболеваний и (или) состояний костно-мышечной системы». ОА как заболевание, которое необходимо диагностировать и лечить, упоминается в серии приказов МЗ РФ от 24.12.2012 «Об утверждении стандарта первичной медико-санитарной помощи...» для различных его локализаций, где единственной врачебной специальностью, имеющей полномочия первичной диагностики ОА, является травматология. Врачи-ревматологи, согласно Приказу МЗ РФ от 12.11.2012 № 900н «Об утверждении Порядка оказания медицинской помощи взрослому населению по профилю «ревматология», должны ставить диагноз ОА и помогать в диагностике данного заболевания врачам других специальностей.

Можно предполагать, что путаница в распределении полномочий в первичной диагностике ОА приводит к различиям практики в разных регионах и, очень вероятно, в разные периоды. Это могло стать главной причиной столь значительных вариаций в трендах данного показателя во всех трех анализируемых популяциях и внутри каждой из них.

При недостатке возможностей регистрации ОА анализ данных приблизителен. В нашем исследовании зарегистрировано увеличение общей заболеваемости ОА среди взрослого населения РФ, СЗФО и АО в период с 1994 по 2018 г. на 495\%, 254\% и 276\% соответственно. При этом оценки за 2018 г. различаются тоже очень существенно: от 3850 на 100 тыс. населения в РФ до 5399 на 100 тыс. населения в СЗФО. Из ежегодно публикуемых 
отчетов ревматологических служб приводятся различающиеся данные по приросту первичной и общей заболеваемости ОА. Например, по данным В.А. Насоновой и соавт., в 1996 г. распространенность ОА составила 990 на 100 тыс. взрослого населения, а динамика роста в период с 1994 по 1998 г. составила +44\% [2]. Аналогичная приблизительная описательная картина опубликована в ведущих ревматологических журналах по заболеваемости ОА. Например: «за период с 2011 по 2016 г. заболеваемость ОА увеличилась на $11 \%$, с 2,8\%о в 1996 г. выросла до 6,7\%о в 2016 г., что составило +139\%. Рост заболеваемости в 1994-1998 гг. составил 25\%, тогда как в 2011-2016 гг. заболеваемость выросла всего на 6,3\%» [25].

Известно, что наиболее высокая общая заболеваемость ОА наблюдается у населения старше 65 лет в этой группе она достигает $80 \%$. При этом в течение последних лет наблюдается старение населения РФ [25], связанное с уменьшением рождаемости и увеличением продолжительности жизни. Для нивелирования влияния этого явления на заболеваемость ОА необходимо проводить стандартизацию по возрасту. В стандартизованной государственной форме отчетности № 12 отсутствуют сведения о возрасте и поле пациентов с регистрируемыми заболеваниями, хотя при ОА эти факторы очень важны. Метод прямой стандартизации можно применять только при наличии персонифицированных данных, которые доступны в регистре больных ОА. Проект такого регистра был сформирован еще в 2006 г. по примеру онкологических регистров, успешно осуществляющих свою деятельность на территории РФ как минимум с начала 2000-х годов и способных выступать в качестве надежного ресурса как для практической, так и для научной деятельности [29]. Данные обо всех пациентах с установленным диагнозом ОА должны быть внесены в единую базу, которая ведется в областных ревматологических центрах РФ. С определенной периодичностью эти данные должны передаваться в ФГБНУ НИИР им. В.А. Насоновой для обработки. Однако до настоящего времени такой учет пациентов не ведется. В настоящее время без единого регистра мы лишь опосредованно судим о неких «неблагоприятных демографических тенденциях, наметившихся в последние десятилетия», которые позволяют «законо-

\section{Л И TEPAT Y PA / REFERENCES}

1. Woolf A, Pfleger B. Burden of major musculoskeletal conditions. Bull World Health Organ. 2003;81:646-656.

2. Насонова ВА, Фоломеева ОМ, Амирджанова ВН, Якушева ЕО, Лобарева ЕС, Логинова ЕЮ. Болезни костномышечной системы и соединительной ткани в России: динамика статистических показателей за 5 лет (1994-1998 гг.). Научно-практическая ревматология. 2000;38(2):4-12.

[Nasonova VA, Folomeeva OM, Amirjanova VN, Yakusheva EP, Lobareva ES, Loginova EYu. Musculoskeletal and connective tissue diseases in Russia: Dynamics of statistical indices for 5 years (1994-1998). Nauchcno-Prakticheskaya Revmatologia $=$ Rheumatology Science and Practice. 2000;38(2):4-12 (In Russ.)]. doi: 10.14412/1995-4484-2000-1226

3. Балабанова РМ, Дубинина ТВ, Эрдес ШФ. Динамика заболеваемости ревматическими заболеваниями взрослого населения России за 2010-2014 гг. Научно-практическая ревматология. 2016;54(3):266-270. [Balabanova RM, Dubinina TV, Erdes ShF. Trends in the incidence of rheumatic diseases in the adult population of Russia over 2010-2014. Nauchcno-Prakticheskaya мерно предположить более быстрые темпы роста заболеваемости ОА» [25].

В целом очевидно, что несовершенство регистрации статистических данных по ОА ставит под сомнение их надежность. Назрела необходимость создания регистра ОА, способного на основе персонифицированных данных больных обеспечить качественный учет заболеваемости. Более глубокий анализ существующей системы регистрации ОА по данным определенных лечебных учреждений отдельно взятого областного центра (г. Архангельск) запланирован в следующей работе.

\section{Заключение}

Анализ официальной статистической информации о первичной и общей заболеваемости ОА показывает существенную вариацию показателей; их колебания никак не связаны с изменениями в практике диагностики и лечения этого заболевания и могут быть обусловлены пробелами в его регистрации. Существующая система статистического учета ОА не персонифицирована, не учитывает пол и возраст больных. Улучшение эпидемиологической оценки ОА возможно при внедрении в практику системы персонифицированного учета пациентов - регистра ОА по примеру онкологических регистров, регистров родов и др., которые уже существуют на территориях РФ. Для пилотного исследования можно ввести такой регистр в одном субъекте - Архангельской области - и провести сравнение с официальными данными статистики. При положительном результате можно рекомендовать внедрение персонифицированной регистрации ОА в РФ.

\section{Прозрачность исследования}

Исследование не имело спонсорской поддержки. Авторы несут полную ответственность за предоставление окончательной версии рукописи в печать.

\section{Декларация о финансовых и других взаимоотношениях}

Окончательная версия рукописи была одобрена всеми авторами. Авторы не получали гонорар за исследование. Все авторы принимали участие в разработке концепции статьи и в написании рукописи.
Revmatologia $=$ Rheumatology Science and Practice. 2016;54(3):266270 (In Russ.)]. doi: 10.14412/1995-4484-2016-266-270

4. Балабанова РМ, Дубинина ТВ, Демина АБ, Кричевская ОА. Заболеваемость болезнями костно-мышечной системы в Российской Федерации за 2015-2016 гг. Научно-практическая ревматология. 2018;56(1):15-21. [Balabanova RM, Dubinina TV, Demina AB, Krichevskaya OA. The incidence of musculoskeletal diseases in the Russian Federation over 2015-2016. NauchcnoPrakticheskaya Revmatologia $=$ Rheumatology Science and Practice. 2018;56(1):15-21 (In Russ.)]. doi: 10.14412/1995-4484-2018-15-21

5. Балабанова РМ, Эрдес ШФ. Динамика распространенности ревматических заболеваний, входящих в ХІІІ класс МКБ-10, в популяции взрослого населения Российской Федерации за 2000-2010 гг. Научно-практическая ревматология. 2012;50(3):10-12. [Balabanova RM, Erdes SF. The incidence and prevalence of rheumatic diseases in Russia in 2012-2013.

Nauchcno-Prakticheskaya Revmatologia = Rheumatology Science and Practice. 2015;53(2):120-124 (In Russ.)]. doi: 10.14412/19954484-2012-702 
6. Беневоленская ЛИ, Бржезовский ММ. Эпидемиология ревматических болезней. М.:Медицина;1988:235.

[Benevolenskaya LI, Brzhezovsky MM. Epidemiology of rheumatic diseases. Moscow:Meditsina;1988:235 (In Russ.)].

7. Приказ Министерства экономического развития Российской Федерации, Федеральной службы государственной статистики от 24.12.2018 N 773 «Об утверждении форм федерального статистического наблюдения с указаниями по их заполнению для организации министерством здравоохранения Российской Федерации федерального статистического наблюдения в сфере охраны здоровья». [Order of the Ministry of Economic Development of the Russian Federation, Federal State Statistics Service d.d. December 24, 2018 N 773 "On the approval of federal statistical observation forms with instructions for filling them out for the organization of federal statistical observation in the field of health protection by the Ministry of Health of the Russian Federation» (In Russ.)].

8. Altman R, Alarcon G, Appelrouth D, Bloch D, Borenstein D, Brandt K. The American College of Rheumatology criteria for the classification and reporting of osteoarthritis of the hip. Arthritis Rheum. 1991;34:505-514.

9. Федеральная служба государственной статистики, Управление Федеральной службы государственной статистики по Архангельской области и Ненецкому автономному округу (Архангельскстат). Статистический ежегодник Архангельской области 2010 г. Архангельск:Архангельскст ат;2011. [Federal State Statistics Service, Administration of the Federal State Statistics Service for the Arkhangelsk Region and the Nenets Autonomous District (Arkhangelskstat). Statistical yearbook of the Arkhangelsk Region for 2010.

Arkhangelsk:Arkhangelskstat;2011 (In Russ.)]. URL: https:// arhangelskstat.gks.ru/publication_arh (Дата доступа: 08.10.2021).

10. Федеральная служба государственной статистики, Управление Федеральной службы государственной статистики по Архангельской области и Ненецкому автономному округу (Архангельскстат). Статистический ежегодник Архангельской области 2011 г. Архангельск:Архангельскстат; 2012. [Federal State Statistics Service, Administration of the Federal State Statistics Service for the Arkhangelsk Region and the Nenets Autonomous District (Arkhangelskstat). Statistical yearbook of the Arkhangelsk Region for 2011.

Arkhangelsk:Arkhangelskstat; 2012 (In Russ.)]. URL: https:// arhangelskstat.gks.ru/publication_arh (Дата доступа: 08.10.2021).

11. Федеральная служба государственной статистики,

Управление Федеральной службы государственной статистики по Архангельской области и Ненецкому автономному округу (Архангельскстат). Статистический ежегодник Архангельской области 2012 г. Архангельск:Архангельскст aт;2013. [Federal State Statistics Service, Administration of the Federal State Statistics Service for the Arkhangelsk Region and the Nenets Autonomous District (Arkhangelskstat). Statistical yearbook of the Arkhangelsk Region for 2012.

Arkhangelsk:Arkhangelskstat;2013 (In Russ.)]. URL: https:// arhangelskstat.gks.ru/publication_arh (Дата доступа: 08.10.2021).

12. Федеральная служба государственной статистики,

Управление Федеральной службы государственной статистики по Архангельской области и Ненецкому автономному округу (Архангельскстат). Статистический ежегодник Архангельской области 2013 г. Архангельск:Архангельскст ат;2014. [Federal State Statistics Service, Administration of the Federal State Statistics Service for the Arkhangelsk Region and the Nenets Autonomous District (Arkhangelskstat). Statistical yearbook of the Arkhangelsk Region for 2013.

Arkhangelsk:Arkhangelskstat;2014 (In Russ.)]. URL: https:// arhangelskstat.gks.ru/publication_arh (Дата доступа: 08.10.2021).

13. Федеральная служба государственной статистики,

Управление Федеральной службы государственной статистики по Архангельской области и Ненецкому автономному округу (Архангельскстат). Статистический ежегодник Архангельской области 2014 г. Архангельск:Архангельскст ат;2015. [Federal State Statistics Service, Administration of the Federal State Statistics Service for the Arkhangelsk Region and the Nenets Autonomous District (Arkhangelskstat). Statistical yearbook of the Arkhangelsk Region for 2014.

Arkhangelsk:Arkhangelskstat;2015 (In Russ.)]. URL: https:// arhangelskstat.gks.ru/publication_arh (Дата доступа: 08.10.2021).

14. Федеральная служба государственной статистики, Управление Федеральной службы государственной статистики по Архангельской области и Ненецкому автономному округу (Архангельскстат). Статистический ежегодник Архангельской области 2015 г. Архангельск:Архангельскст aт;2016. [Federal State Statistics Service, Administration of the Federal State Statistics Service for the Arkhangelsk Region and the Nenets Autonomous District (Arkhangelskstat). Statistical yearbook of the Arkhangelsk Region for 2015.

Arkhangelsk:Arkhangelskstat;2016 (In Russ.)]. URL: https:// arhangelskstat.gks.ru/publication_arh (Дата доступа: 08.10.2021).

15. Федеральная служба государственной статистики, Управление Федеральной службы государственной статистики по Архангельской области и Ненецкому автономному округу (Архангельскстат). Статистический ежегодник Архангельской области 2016 г. Архангельск:Архангельскст aт;2017. [Federal State Statistics Service, Administration of the Federal State Statistics Service for the Arkhangelsk Region and the Nenets Autonomous District (Arkhangelskstat). Statistical yearbook of the Arkhangelsk Region for 2016. Arkhangelsk:Arkhangelskstat;2017 (In Russ.)]. URL: https:// arhangelskstat.gks.ru/publication_arh (Дата доступа: 08.10.2021).

16. Федеральная служба государственной статистики, Управление Федеральной службы государственной статистики по Архангельской области и Ненецкому автономному округу (Архангельскстат). Статистический ежегодник Архангельской области 2017 г. Архангельск:Архангельскст aт;2018. [Federal State Statistics Service, Administration of the Federal State Statistics Service for the Arkhangelsk Region and the Nenets Autonomous District (Arkhangelskstat). Statistical yearbook of the Arkhangelsk Region for 2017. Arkhangelsk:Arkhangelskstat;2018 (In Russ.)]. URL: https:// arhangelskstat.gks.ru/publication_arh (Дата доступа: 08.10.2021).

17. Федеральная служба государственной статистики, Управление Федеральной службы государственной статистики по Архангельской области и Ненецкому автономному округу (Архангельскстат). Статистический ежегодник Архангельской области 2018 г. Архангельск:Архангельскст aт;2019. [Federal State Statistics Service, Administration of the Federal State Statistics Service for the Arkhangelsk Region and the Nenets Autonomous District (Arkhangelskstat). Statistical yearbook of the Arkhangelsk Region for 2018.

Arkhangelsk:Arkhangelskstat;2019 (In Russ.)]. URL: https:// arhangelskstat.gks.ru/publication_arh (Дата доступа: 08.10.2021).

18. Александрова ГА, Поликарпов АВ, Огрызко ЕВ, Голубев НА, Кадулина НА, Беляева ИМ, и др. Заболеваемость взрослого населения России в 2014 году. Статистические материалы. M.;2015:165. [Aleksandrova GA, Polikarpov AV, Ogryzko EV, Golubev NA, Kadulina NA, Belyaeva IM, et al. The incidence of the adult population of Russia in 2014. Statistical materials. Moscow;2015:165 (In Russ.)]. URL: https://minzdrav.gov.ru/ministry/61/22/stranitsa-979/statisticheskie-i-informatsionnye-materialy/statisticheskiy-sbornik-2014-god (Дата доступа: 08.10.2021).

19. Александрова ГА, Поликарпов АВ, Голубев НА, Оськов ЮИ, Кадулина НА, Беляева ИМ, и др. Заболеваемость взрослого населения России в 2015 году. Статистические материалы. M.;2016:159. [Aleksandrova GA, Polikarpov AV, Golubev NA, Oskov YuI, Kadulina NA, Belyaeva IM, et al. The incidence of the adult population of Russia in 2015. Statistical materials. Moscow;2016:159 (In Russ.)]. URL: https://minzdrav.gov.ru/ministry/61/22/stranitsa-979/statisticheskie-i-informatsionnye-materialy/statisticheskiy-sbornik-2015-god (Дата доступа: 08.10.2021).

20. Александрова ГА, Поликарпов АВ, Голубев НА, Оськов ЮИ, Кадулина НА, Беляева ИМ, и др. Заболеваемость взрослого 
населения России в 2016 году. Статистические материалы. M.;2017:161. [Aleksandrova GA, Polikarpov AV, Golubev NA, Oskov YuI, Kadulina NA, Belyaeva IM, et al. The incidence of the adult population of Russia in 2016. Statistical materials. Moscow;2017:161 (In Russ.)]. URL: https://minzdrav.gov.ru/ministry/61/22/stranitsa-979/statisticheskie-i-informatsionnye-materialy/statisticheskiy-sbornik-2016-god (Дата доступа: 08.10.2021).

21. Поликарпов АВ, Александрова ГА, Голубев НА, Тюрина ЕМ, Оськов ЮИ, Шелепова ЕА. Заболеваемость взрослого населения России в 2017 году. Статистические материалы. M.;2018:160. [Polikarpov AV, Aleksandrova GA, Golubev NA, Tyurina EM, Oskov YuI, Shelepova EA. The incidence of the adult population of Russia in 2017. Statistical materials.

Moscow;2018:160 (In Russ.)]. URL: https://minzdrav.gov.ru/ministry/61/22/stranitsa-979/statisticheskie-i-informatsionnye-materialy/statisticheskiy-sbornik-2017-god (Дата доступа: 08.10.2021).

22. Титова ЛВ, Макарова МВ. Анализ заболеваемости ревматическими заболеваниями в Архангельской области: динамика статистических показателей за 2010-2015 гг. Научнопрактическая ревматология. 2017;55(5):521-525. [Titova LV, Makarova MV. Analysis of the incidence of rheumatic diseases in the Arkhangelsk region: Trends in the 2010-2015 statistical characteristics. Nauchcno-Prakticheskaya Revmatologia $=$ Rheumatology Science and Practice. 2017;55(5):521-525 (In Russ.)]. doi: 10.14412/1995-4484-2017-521-525

23. Ассоциация ревматологов России. Федеральные клинические рекомендации по диагностике и лечению остеоартроза. M.;2013. [Association of Rheumatologists of Russia. Federal clinical guidelines for the diagnosis and treatment of osteoarthritis. Moscow;2013 (In Russ.)]. URL: https://rheumatolog.ru/experts/ klinicheskie-rekomendacii (Дата доступа: 08.10.2021).

24. Насонов ЕЛ, Насонова ВА, Фоломеева ОМ. Ревматические болезни и ревматологическая служба в Центральном Федеральном округе России. Научно-практическая ревматология. 2005;43(4):4-7. [Nasonov EL, Nasonova VA, Folomeeva OM. Rheumatic diseases and rheumatological service in the Central Federal District of Russia. Nauchcno-Prakticheskaya
Revmatologia $=$ Rheumatology Science and Practice. 2005;43(4):4-7 (In Russ.)]. doi: 10.14412/1995-4484-2005-609

25. Кабалык МА. Распространенность остеоартрита в России: региональные аспекты динамики статистических показателей за 2011-2016 гг. Научно-практическая ревматология. 2018;56(4):416-422. [Kabalyk MA. Prevalence of osteoarthritis in Russia: Regional aspects of trends in statistical parameters during 2011-2016. Nauchcno-Prakticheskaya Revmatologia $=$ Rheumatology Science and Practice. 2018;56(4):416-422 (In Russ.)]. doi: 10.14412/1995-4484-2018416-422

26. Балабанова РМ, Эрдес ШФ. Ревматические заболевания у взрослого населения в федеральных округах России. Научно-практическая ревматология. 2014;52(1):5-7.

[Balabanova RM, Erdes SF. Rheumatic diseases in the adult population in Federal districts of Russia. Nauchcno-Prakticheskaya Revmatologia $=$ Rheumatology Science and Practice. 2014;52(1):5-7 (In Russ.)]. doi: 10.14412/1995-4484-2014-5-7

27. Приказ Министерства здравоохранения и социального развития РФ от 17.01.2005 N 84 «О порядке осуществления деятельности врача общей практики (семейного врача)» [Order of the Ministry of Health and Social Development of the Russian Federation d.d. January 17, $2005 \mathrm{~N} 84$ "On the procedure for performing the activities of a general practitioner (family doctor)" (In Russ.)].

28. Профессиональные стандарты и справочники должностей. Здравоохранение. [Professional standards and job reference books. Healthcare (In Russ.)]. URL: https://classdoc.ru/profstandart/02_health (Дата доступа: 08.10.2021).

29. Вальков МЮ., Карпунов АА., Коулман МП., Аллемани К, Панкратьева АЮ, Потехина ЕФ, и др. Популяционный раковый регистр как ресурс для науки и практического здравоохранения. Экология человека. 2017;5:54-62. [Valkov MYu, Karpunov AA, Coleman MP, Allemani C, Pankratieva AYu, Potekhina EF, et al. The population-based cancer registry as a resource for research and practical healthcare. Human Ecology. 2017;5:54-62 (In Russ.)]. 